\title{
Serum levels of the S100B protein and neuron-specific enolase are associated with mortality in critically ill patients
}

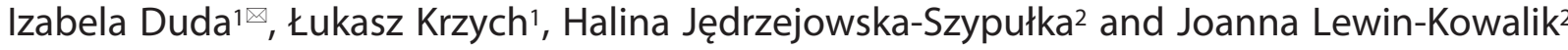 \\ 1Department of Anesthesiology and Intensive Care, School of Medicine in Katowice, Medical University of Silesia, Katowice, Poland; ${ }^{2}$ Depart- \\ ment of Physiology, School of Medicine in Katowice, Medical University of Silesia, Katowice, Poland
}

\begin{abstract}
Introduction. Evaluation of the prognostic potential of the S100B protein and neuron-specific enolase (NSE) as predictors of mortality in critically ill patients in intensive care units (ICU). Materials and Methods. The study was conducted on 62 patients. Basic clinical variables and blood samples for S100B and NSE level testing were obtained during the first four days after admission. Mortality was described as the patient's death during hospitalization in the ICU. Results. $35 \%$ of the patients had died. The level of S100B and NSE was significantly higher in non-survivors in comparison with survivors ( $p=0.007$ and $p=0.02$, respectively). Mortality risk was significantly higher in patients with higher levels of biomarkers than the reference values for S100B (OR 9.00; $95 \% \mathrm{Cl} 2.38-33.99 ; p<0.001$ ) as well as for NSE (OR 5.75; $95 \% \mathrm{Cl} 1.31-25.27 ; p=0.016)$. Receiver operating characteristic proved that $\mathrm{S} 100 \mathrm{~B}$ is a better mortality predictor than NSE (AUC 0.76 for S100B and 0.68 for NSE). From all the other variables, the Apache II score turned out to be the only significant predictor of mortality (AUC 0.88). Conclusion. There is a significant correlation between mortality in the ICU and increased serum concentration of S100B and NSE. This correlation is stronger for S100B. Testing for serum levels of S100B and NSE may be useful for prediction of treatment outcomes in the ICU patients.
\end{abstract}

Key words: S100B, neuron-specific enolase, mortality, critically ill

Received: 07 June, 2017; revised: 18 August, 2017; accepted: 16 October, 2017; available on-line: 10 December, 2017

e-mail: izaduda@neostrada.p

Abbreviations: AUC, area under the curve; CRP, C-reactive protein ROC, receiver operated characteristic; ICU, Intensive Care Unit; NSE, a neuron-specific enolase

\section{INTRODUCTION}

Although the mortality rate in the intensive care unit (ICU) has tended to decrease over the last few decades, it is still high, with estimates suggesting a rate of over 40\% in Poland (Adamski et al., 2015; Weigl et al., 2017). The APACHE (Acute Physiology and Chronic Health Evaluation), SAPS (Simplified Acute Physiology Score) and SOFA (Sequential Organ Failure Assessment) are the most common scoring systems used for evaluation of the illness severity and are valuable in predicting treatment outcomes of the patients in the ICU (Del Bufalo et al., 1995; Vincent et al., 1998). At the same time, there is need for additional tools for estimation of the mortality risk based on clinical biomarkers.

Biomarkers are defined as biological molecules that may be used for disease diagnosis or for evaluation of its progression. Many studies attempt to describe a correla- tion between the chosen biological markers and a mortality rate (Jensen et al., 2006; Cruz et al., 2010; Nguyen et al., 2010).

The S100B protein and neuron specific enolase (NSE) are known to be markers of brain damage (Barone et al., 1993; Hermann et al., 1999; Korfias et al., 2006; Korfias et al., 2007; Siman et al., 2011; Zongo et al., 2012; Mecier et al., 2013; Krzych et al., 2015). S100B is a calciumbinding protein accumulated in glial cells, astrocytes and Schwann cells. S100B has been also detected in adipose cells, skin, melanoma, and glioblastoma multiforme. However, its biological function remains unknown (Anderson et al., 2001; Michetti et al., 2012; Donato et al., 2013). NSE is a glycolytic enzyme present in the cytoplasm of neurons, cells of neuroendocrine origin and at lower concentrations in erythrocytes and thrombocytes. It may be also used as a biomarker in lung cancer but its clinical utility is not so clear (Karnak et al., 2005; Xu et al., 2016).

Some recent experimental studies have shown a correlation between $\mathrm{S} 100 \mathrm{~B}$ and NSE with respect to the outcomes of ICU patients (Weigand et al., 2000; Nguyen et al., 2006; Routsi et al., 2006; Macedo et al., 2013; Pfortmueller et al., 2016). In study presented here it was assumed that patients in the ICU with levels of S100B and NSE exceeding the reference values had a significantly higher mortality risk than patients with normal values. A correlation between the level of the tested biomarkers, clinical variables at the beginning of hospitalizationand mortality rate was analyzed.

The study aimed to estimate how useful the testing for serum concentration of S100B and NSE may be for predicting the mortality rate in critically ill patients.

\section{MATERIALS AND METHODS}

The study presented here was prospective and observational. The study was authorized by the Bioethical Committee of Medical University of Silesia in Katowice. According to the terms of approval, consent to participate in the study was not needed.

All patients consecutively admitted to the multidisciplinary 10 bed ICU were enrolled in the study. Exclusion criteria were: age below 18 years, pregnancy, high mortality risk within the next 24 hours, and status post head injury (traumatic and non-traumatic). The study was discontinued when the patient died or was discharged from the ICU. The patients were evaluated considering their age, sex, duration of hospitalization in the ICU, mechanical ventilation, and reason for admission including their status post-surgery and clinical indications. 
Table 1. Demographic and baseline clinical characteristics of patients admitted to ICU

\begin{tabular}{|c|c|c|c|c|}
\hline & $\begin{array}{l}\text { Overall } \\
n=62\end{array}$ & $\begin{array}{l}\text { Non-survivors } \\
n=22\end{array}$ & $\begin{array}{l}\text { Survivors } \\
\mathrm{n}=40\end{array}$ & $p$-value \\
\hline Age (years) [mean \pm S.D.] & $57 \pm 17$ & $69 \pm 15$ & $50 \pm 13$ & $<0.001$ \\
\hline Gender [Female/Male] & $35 / 27$ & $13 / 9$ & $22 / 18$ & 0.966 \\
\hline ICU length of stay (day) [median; IQR] & $9 ; 4-21$ & $10 ; 4-29$ & $19 ; 4-16$ & 0.38 \\
\hline Admission after surgery [n; \%] & $30 ; 48 \%$ & $15 ; 68 \%$ & $15 ; 38 \%$ & 0.041 \\
\hline Mechanical ventilation $[\mathrm{n} ; \%]$ & $55 ; 89 \%$ & $22 ; 100 \%$ & $33 ; 82 \%$ & 0.002 \\
\hline APACHE II score (points) [mean \pm S.D.] & $17 \pm 7$ & $24 \pm 5$ & $13 \pm 6$ & $<0.001$ \\
\hline Lactate (mmol/L) [median; IQR] & $2.6 ; 1.8-3.55$ & $3.10 ; 2.5-3.7$ & $2.1 ; 1.6-3.2$ & 0.004 \\
\hline CRP (mg/L) [median; IQR] & $164.7 ; 48.8-244.9$ & $162.2 ; 88.0-289.44$ & $138.5 ; 33.8-217.1$ & 0.032 \\
\hline Creatinine (mg/dL) [median; IQR] & $1.24 ; 0.91-2.13$ & $1.64 ; 1.29-4.05$ & $1.00 ; 0.83-1.39$ & $<0.001$ \\
\hline
\end{tabular}

Data are presented as mean and standard deviation (S.D.) or median and interquartile range (IQR), or number (n) and percentage (\%). $\mathrm{APACHE}=$ Acute Physiologic and Chronic Health Evaluation; ICU=intensive care unit; $C R P=C$-reactive protein; NSE=neuron-specific enolase

Mortality was described as the patient's death during hospitalization in the ICU. Laboratory testing (lactate, C-reactive protein $[\mathrm{CRP}]$, creatinine) was performed at least once a day. The severity of the patient's condition was assessed on admission using the APACHE II Scoring System. Every day, for four days after admission, venous blood was sampled for S100B and NSE testing. The blood samples were centrifuged immediately after sampling at $3000 \mathrm{rpm}$ for 10 minutes. Supernatant was separated and stored at $-80^{\circ} \mathrm{C}$ for further analysis.

Commercial ELISA enzyme immunometric assay kit (S100B: Human S100B ELISA, Biovendor, Czech Republic; NSE: CanAng NSE EIA, Fujirebio Diagnostic AB, Sweden) was used for quantitative testing of the serum levels of S100B and NSE. The reference value for S100B amounted to $<0.12 \mu \mathrm{g} / \mathrm{L}$ and for NSE to $<15 \mathrm{ng} / \mathrm{mL}$.

Statistical analysis. The quantitative variables are presented as a mean and standard deviation (those normally distributed) or a median and interquartile range (IQR) (non-normally distributed). The qualitative variables are presented as an absolute value and a percentage. Quantitative variables were correlated using Kendall's rank correlation coefficient and Spearman's rank correlation coefficient. The $U$ Mann-Whitney test was used to assess whether concentrations of biomarkers were higher in non-survivors. The correlation between biomarkers and survival or death was analyzed based on contingency tables supported with the Chi-squared test for assessment of a stochastic relationship between variables. The effect size was measured using odds ratios, which was reported along with a confidence interval of 95\%. For modeling of the biomarker influence on mortality risk (together or separately) the logistic regression model was used. The quality of all the models was described using receiver operated characteristic (ROC) curves and calculation of the area under the curve (AUC). For all calculations, the "R" statistical software package was used, version 3.2.3. Statistical significance was defined as $p<0.05$.

\section{RESULTS}

A total of 98 patients admitted to the ICU were enrolled in the study and 36 of them were excluded (Fig. 1). Clinical, demographic and biological data of all the patients is presented in Table 1. Regarding reason for admission and clinical indications, there were $16 \mathrm{pa}-$ tients with sepsis/septic shock, 10 subjects after sudden cardiac arrest, 9 individuals with neurological disorders other than brain injury, 6 subjects with acute pancreatitis, 5 patients with exacerbation of chronic pulmonary diseases (COPD, asthma), 4 women after obstetric procedure complicated with eclampsia, 3 patients with hemorrhagic shock, and 9 with other conditions. During hospitalization in the ICU 22 patients had died (35\%). The patients who died in comparison to the patients discharged from ICU had significantly higher levels of S100B (median 0.60 [IQR 0.02-0.78] $\mu \mathrm{g} / \mathrm{mL} v \mathrm{~s}$. median 0.08 [IQR 0.00-0.07] $\mu \mathrm{g} / \mathrm{L} ; \mathrm{p}=.007$ ) and NSE (median 25.74 [IQR 5.23-23.40] ng/mL vs. median 7.57 [IQR 2.01-7.81] ng/mL; $p=0.02$ ) (Fig. 2).

In total, 163 samples of $\mathrm{S} 100 \mathrm{~B}$ and 163 samples of NSE were obtained. The level of S100B exceeded the reference value $(>0.12 \mu \mathrm{g} / \mathrm{L})$ in 45 samples $(28 \%)$. The NSE level exceeded the reference value $(>15 \mathrm{ng} / \mathrm{L})$ in 24 samples $(15 \%)$. The highest value of S100B amounted to $2.55 \mu \mathrm{g} / \mathrm{L}$ and of NSE to $200 \mathrm{ng} / \mathrm{L}$.

Patients with an increased level of S100B and NSE had significantly higher mortality risk in comparison to patients with levels of S100B and NSE within the reference values (Table 2).

S100B $(p=0.003)$ as well as NSE $(p=0.021)$ were related to predicted mortality risk (Table 3 ). For NSE, the correlation was related to $\mathrm{S} 100 \mathrm{~B}$, whereas S100B influenced the mortality risk independently of NSE (Fig. 3).

Logistic regression models were used for analysis of additional predicates, which may improve estimation of

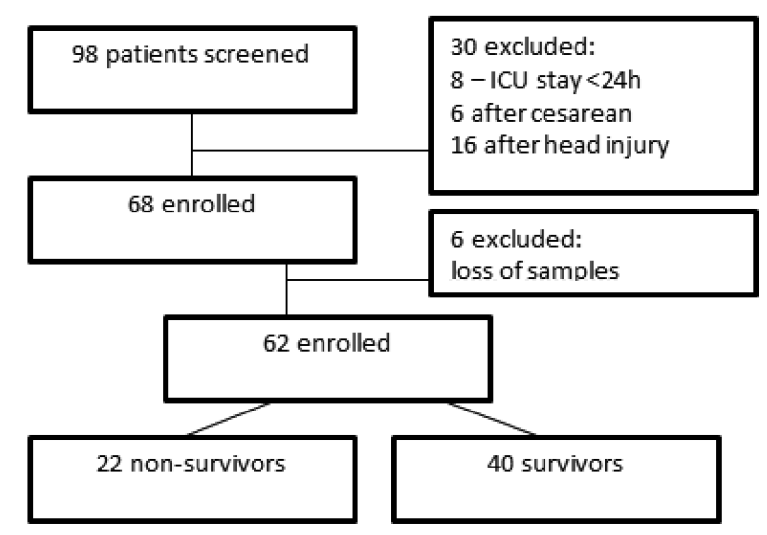

Figure 1. Flow chart of patients included in this study 


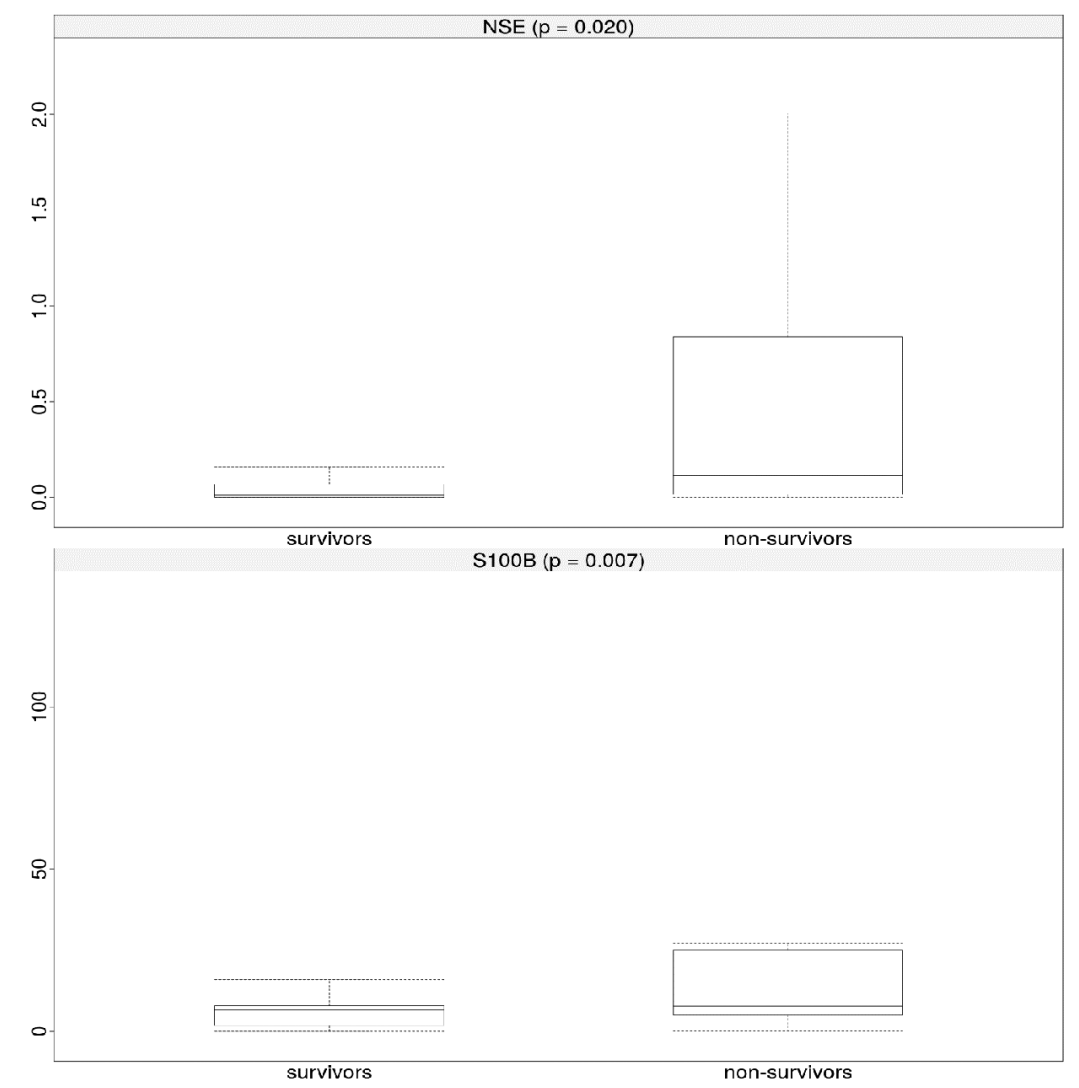

Figure 2. Plasma concentration of NSE and S100B in survivors and non-survivor patientsWhiskers indicate minimum and maximum range

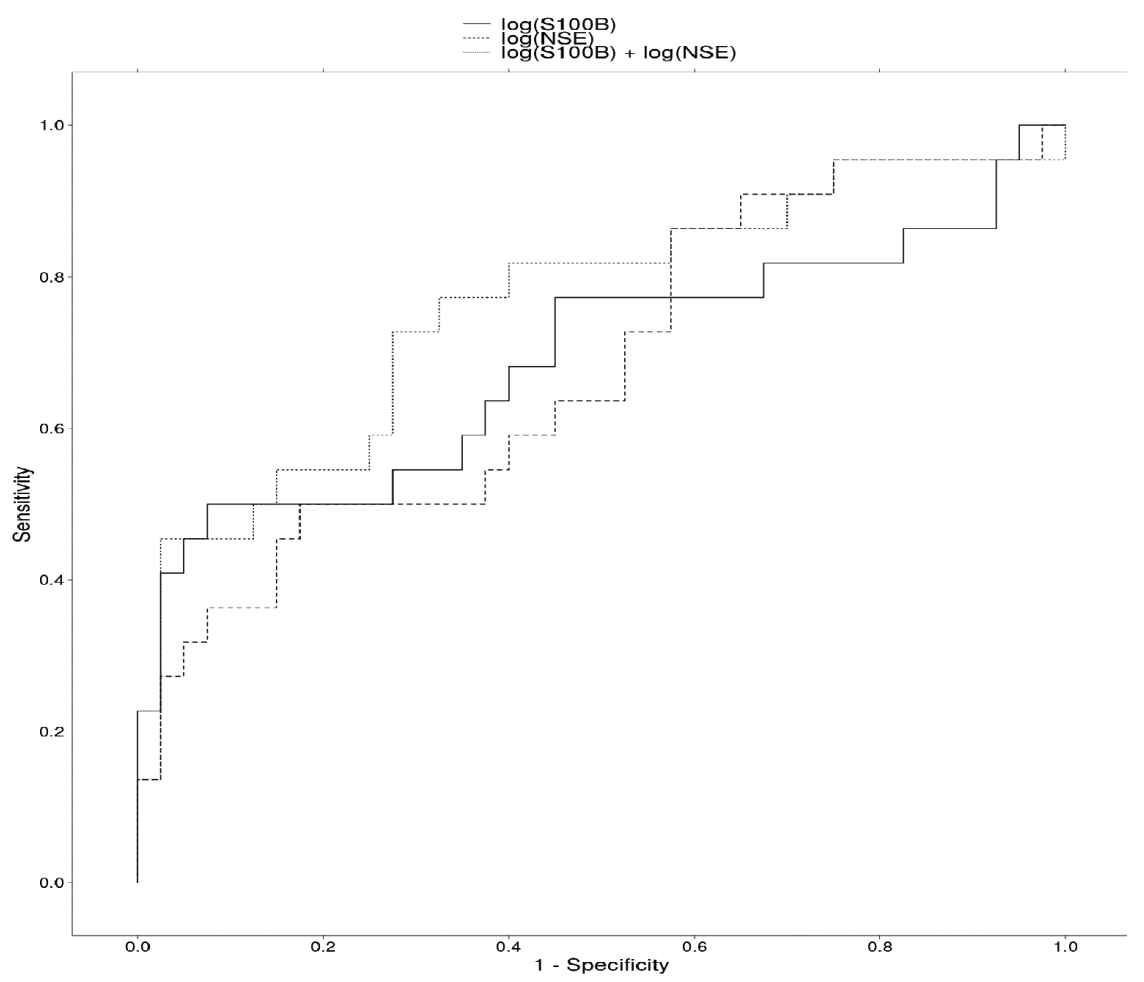

Figure 3. ROC (receiver operating curve) analysis for models: $\log (\mathrm{S} 100 \mathrm{~B}), \log (\mathrm{NSE})$ and $\log (\mathrm{S} 100 \mathrm{~B})+\log (\mathrm{NSE})$ AUC (area under the curve): $0.70 ; 0.68 ; 0.76$, respectively 
Table 2. The risk of death in patients with elevated levels of S100B and NSE

\begin{tabular}{|c|c|c|c|c|c|c|c|c|c|}
\hline & Limit & Survivors & Non-survivors & $x^{2}$ & $\mathrm{p}$ & OR & OR CI 95\% & $\mathrm{R}$ & $\Delta \mathrm{R} \mathrm{Cl} 95 \%$ \\
\hline \multirow{2}{*}{ S100B } & Limit- & 36 & 11 & \multirow{2}{*}{12.38} & \multirow{2}{*}{$<0.001$} & \multirow{2}{*}{9} & \multirow{2}{*}{$2.38-33.99$} & 0.27 & \multirow{2}{*}{$0.24-0.75$} \\
\hline & Limit+ & 4 & 11 & & & & & 0.76 & \\
\hline \multirow{2}{*}{ NSE } & Limit- & 37 & 15 & \multirow{2}{*}{6.20} & \multirow{2}{*}{0.02} & \multirow{2}{*}{5.75} & \multirow{2}{*}{$1.31-25.27$} & 0.29 & \multirow{2}{*}{$0.04-0.78$} \\
\hline & Limit+ & 3 & 7 & & & & & 0.70 & \\
\hline
\end{tabular}

Limit +: S100B> $0.12 \mu \mathrm{g} / \mathrm{mL}$; NSE> $15 \mathrm{ng} / \mathrm{mL}$

$X 2$, test statistic; $p$, the level of significance of the test; $\mathrm{Cl} 95 \%, 95 \%$ confidence interval; OR, odds ratio; $\mathrm{R}$, risk (probability) of death in this group; $\Delta \mathrm{R}$, the difference in risk (group above normal, normal)

Table 3. Logistic regression relationship between the level of S100B and NSE and the risk of death

\begin{tabular}{|c|c|c|c|c|c|}
\hline Model & Coefficient & Estimate & Standard error & $Z$ value & $P$ \\
\hline \multirow{2}{*}{$\begin{array}{l}\log 5100 B \\
(n=62)\end{array}$} & constant & 1.31 & 0.73 & 1.80 & 0.073 \\
\hline & $\log S 100 B$ & 1.16 & 0.38 & 3.01 & 0.003 \\
\hline \multirow{2}{*}{$\begin{array}{l}\text { NSE } \\
(n=62)\end{array}$} & constant & -1.57 & 0.54 & -2.93 & 0.003 \\
\hline & $\log N S E$ & 0.53 & 0.23 & 2.31 & 0.021 \\
\hline \multirow{3}{*}{$\begin{array}{l}\text { S100B + NSE } \\
(n=62)\end{array}$} & constant & 0.71 & 1.00 & 0.71 & 0.475 \\
\hline & $\log 5100 B$ & 1.01 & 0.42 & 2.41 & 0.016 \\
\hline & $\log N S E$ & 0.21 & 0.24 & 0.90 & 0.369 \\
\hline
\end{tabular}

mortality risk (lactate, CRP, creatinine, length of stay, APACHE II score). The APACHE II score was also a significant predictor of mortality (AUC ROC $=0.91$ ) (Fig. 4).

The levels of biomarkers observed in each of the four days were similar. However, for NSE the statistical significance approached the borderline value $(p=0.006)$ and the NSE level was the highest on the fourth day of testing (Fig. 5).

\section{DISCUSSION}

This study indicates that increased levels of S100B and NSE are related to decreased survival in critically ill patients in the ICU. The levels of S100B and NSE

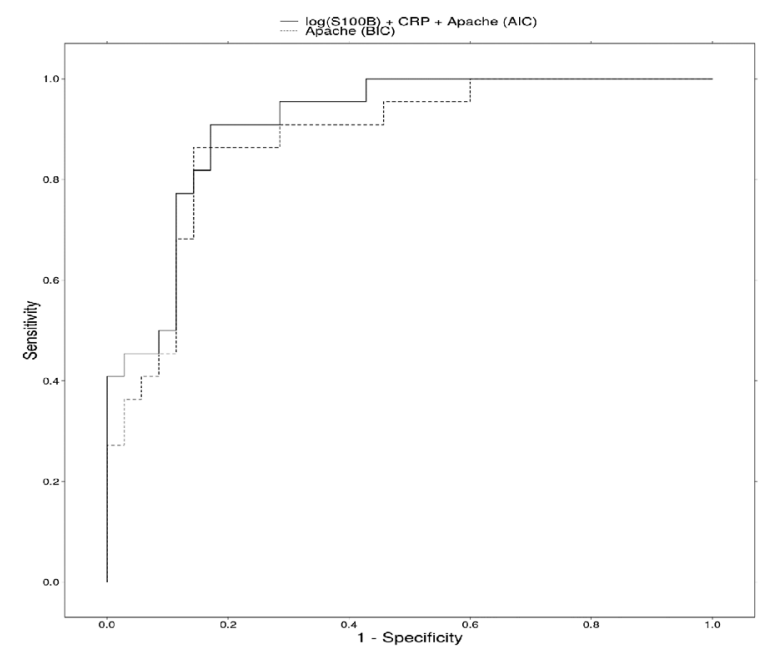

Figure 4. ROC (receiver operating curve) analysis for models: $\log (\mathrm{S} 100 \mathrm{~B})+\mathrm{CRP}+$ Apache II (AIC criterion) and Apache II (BIC criterion) AUC (area under the curve) 0.91 for the AIC model and $\mathbf{0 . 8 8}$ for the BIC model AIC, Akaike information criterion; $\mathrm{BIC}$, Bayesian information criterion were significantly higher in those patients who did not survive. The level of S100B was almost ten times higher in this group. Mortality risk in patients diagnosed with levels of both biomarkers above the reference value was significantly higher in comparison to the patients with normal marker concentrations.

The reference value assessed based on healthy volunteers is $<0.12 \mu \mathrm{g} / \mathrm{L}$ for $\mathrm{S} 100 \mathrm{~B}$ serum levels and $<15$ $\mathrm{ng} / \mathrm{mL}$ for NSE serum levels. The reference value also depends on the method used for immunometric analysis (Diez et al., 1993; Satoh et al., 2002; Zongo et al., 2012). For other tests, the reference value for S100B amounts to $0.15 \mu \mathrm{g} / \mathrm{L}$ and levels $>0.5 \mu \mathrm{g} / \mathrm{L}$ are considered to be

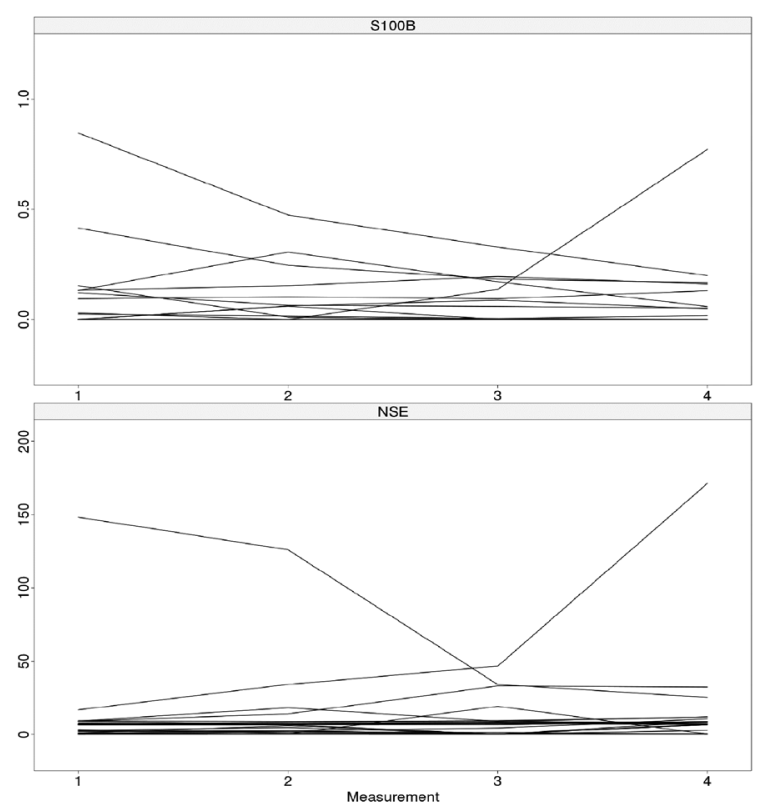

Figure 5. The serum levels of S100B and NSE over the four days of the study. The measurements do not differ significantly (S100B $p=0.731$; NSE $p=0.054$ ) 
abnormal (Stranjalis et al., 2004; Korfias et al., 2007). In this study, the average value of S100B and NSE in the survivors remained within the reference values. In the Routsi and coworkers (2006)study, increased levels of $\mathrm{S} 100 \mathrm{~B}$ were detected in $90 \%$ of samples obtained from critically ill patients in the ICU. In our study, the reference value for $\mathrm{S} 100 \mathrm{~B}$ was exceeded in $28 \%$ of samples. The difference may be caused by different methods of laboratory diagnostics.

Logistic regression analysis was used to estimate which of the studied biomarkers correlates more with an increased mortality risk. S100B exerts a stronger influence on mortality rate with odds ratio amounting to 9.0. For NSE the correlation was related to S100B. The ROC curve demonstrates this, as the $\mathrm{S} 100 \mathrm{~B}$ model covers a larger area than the NSE model. These results are consistent with the Yao and coworkers (2014) study, in which S100B was a better marker than NSE for predicting outcomes in patients with sepsis-associated encephalopathy. Both biomarkers were significantly increased in patients with encephalopathy in comparison to the patients with sepsis but without encephalopathy. However, statistical significance was higher for S100B than for NSE in predicting the hospital mortality rate (Yao et al., 2014).

In the Nguyen and coworkers (2006) study, both biomarkers were tested in patients with sepsis and septic shock. The level of S100B correlated with a higher mortality rate in comparison with the NSE level, although this correlation was not strong and the area under the ROC curve amounted to 0.60 . Both biomarkers turned out to be good predictors of early mortality in the ICU (within the first 72 hours after admission). The area under the ROC curve amounted to 0.83 . In the study presented here, the predictive strength for $\mathrm{S} 100 \mathrm{~B}$ and NSE is intermediate (the area under the ROC curve amounts to 0.71 ) but it should be noted that this study concerns all deaths that occurred during hospitalization in the ICU.

The Weigand and coworkers (2000) study has brought contradictory reports. In that study it was discovered that NSE is a better predictor than S100B in surgical patients with sepsis and septic shock. The serum level of S100B was similar in both, the survivors and the nonsurvivors.

Sepsis is often accompanied by brain dysfunction that results in increased mortality. The mechanism of this phenomenon is very complex and includes both, inflammatory and non-inflammatory processes, which may induce changes in some regions of the brain. These changes include over-activation of microglia, brain perfusion disorders, blood-brain barrier abnormalities and changes in the nerve transmission (Papadopoulos et al., 2000; Ebersoldt et al., 2007; Marshall et al., 2009). These abnormal processes are reflected in increased levels of the brain damage markers (Stocchetti, 2005; Hamed et al., 2009; Iacobone et al., 2009).

In critically ill patients in the ICU, diagnostics of brain function abnormalities is often impossible to perform because of administration of sedatives and analgesics already on admission. $50 \%$ of the patients included in our study were admitted to the ICU directly after surgery. In this case, assessment of brain damage using biomarkers may be an important tool for the intensive care staff. In critically ill patients in ICU, the level of S100B was also assessed in the Routsi and coworkers study (Routsi et al., 2006). An increased level of S100B was observed in ICU patients without primary brain damage. According to those researchers, this increase reflected brain cell dysfunction and may have been a result of insufficient oxygen supply to the brain. In addition, increased levels of S100B were related to other variables indicating tissue hypoperfusion, such as lactate, $\mathrm{pH}$, low hemoglobin level and arterial oxygen content. In the study presented here, non-survivors had shown a significantly increased level of lactate, CRP and creatinine, which confirms the hypothesis that tissue hypoperfusion in critically ill patients in the ICU results in brain damage. The Pfortmueller and coworkers (2016) study focusing on S100B in patients with major trauma had revealed that the $\mathrm{S} 100 \mathrm{~B}$ level was approximately the same in patients with and without head injury. Furthermore, the concentration of S100B raised above $0.2 \mu \mathrm{g} / \mathrm{L}$ was related to increased mortality.

The results of the Macedo and coworkers (2013) study are contradictory. In that research, the S100B and NSE were not found to be useful in predicting the mortality of critically ill patients admitted to the ICU. In the Macedo study, the blood samples were taken only once, on admission to the ICU. In the study present here, the blood was sampled every day during four days of hospitalization and the calculations were made based on average values.

Since Klaus has published the APACHE Scoring System for the first time in 1981, it has become a gold standard for use in the assessment of illness severity and mortality risk in patients admitted to the ICU (Knaus et al., 1981). In the study presented here, the average Apache score for the non-survivors was significantly higher than for the survivors and amounted to 24 points, which makes the hospital mortality rate approximately $50 \%$. Among additional variables analyzed in order to improve prediction of the mortality risk, aside from S100B and NSE, the strongest predictor was the Apache Scoring System. The area under the ROC curve amounted to 0.91. Similar correlation was described by Yao and coworkers (Yao et al., 2014). The Apache score was higher in patients with sepsis-induced encephalopathy in comparison to the group without encephalopathy. A similar relationship was observed for the tested levels of S100B and NSE.

Although many studies emphasize that biomarkers have the highest predictive value in the first 24 hours after admission to the ICU, the study presented here does not confirm that (Routsi et al., 2006; Rodriguez-Rodriguez et al., 2012; Goyal et al., 2013). The levels of biomarkers were similar on every day of hospitalization. Only the level of NSE was higher in the fourth day of testing; however, this difference was not statistically significant.

This study also had some imperfections. Calculations were made based on the average values of biomarker levels obtained during the four following days. In many cases the highest concentration differed from the lowest, and that may have had an influence on the strength of statistical tests. Furthermore, the group of patients was heterogeneous because of different admission causes. Segregation of the patients into two categories (the clinical and postsurgical patients) was not precise. Patients assigned to this group had sepsis and septic shock, as well as respiratory failure during the postoperative period. Those differences in initial admission reasons might have influenced the mortality rate. However, despite the small number of patients in the two groups, it was possible to perform an adequate statistical sub-analysis to overcome this drawback. We believe, however, that the reason of admission per se was not a strong predictor of concentrations of the biomarkers. Moreover, our study was also limited by a small number of patients enrolled. We did not perform sample size calculations to estimate a number of participants required to reach the primary goal. Our assumptions were based on similar studies performed in the recent years. 
Nevertheless, the obtained results seem to be supported by statistical analysis and consistent with the findings of many previous studies in the field.

\section{CONCLUSION}

There is a significant correlation between mortality in the ICU and increased serum concentration of S100B and NSE. This correlation is stronger for S100B. Testing for serum levels of S100B and NSE may be useful for prediction of treatment outcomes in the ICU patients.

\section{Acknowledgements}

Financial support: Medical University of Silesia, Katowice, Poland (KNW-1-074/N/3/0).

\section{REFERENCES}

Adamski J, Goraj R, Onichimowski D, Gawlikowska E, Weigl W (2015) The differences between two selected intensive care units located in central and northern Europe - preliminary observation. Anaesthesiol Intensive Ther 47: 117-124. doi: 10.5603/AIT.a2015.0010

Anderson RE, Settergren G, Hansson LO (2001) High Serum S100B levels for trauma patients without head injuries. Neurosurgery 49: 1492-1493. https://doi.org/10.1097/00006123-200112000-00056

Barone FC, Clark RK, Price WJ, White RF, Feuerstein GZ, Storer BL, Ohlstein EH (1993) Neuron-specific enolase increases in cerebral and systemic circulation following focal ischemia. Brain Res 623: $77-82$

Cruz D N, de Cal M, Garzotto F, Perazella MA, Lentini P, Corradi V, Ronco C (2010) Plasma neutrophil gelatinase-associated lipocalin is an early biomarker for acute kidney injury in an adult ICU population. Intensive Care Med 36: 444-4451. doi: 10.1007/s00134009-1711-1

Del Bufalo C, Morelli A, Bassein L, Fasano L, Quarta CC, Pacilli AM, Gunella G (1995) Severity scores in respiratory intensive care: APACHE II predicted mortality better than SAPS II. Respir Care 40: 1042-1047

Diez M, Torres A, Ortega L, Maestro M, Hernando F, Gomez A, Picardo A, Granell J, Balibrea JL (1993) Value of serum neuron-specific enolase in nonsmall cell lung cancer. Oncology 50: 127-131

Donato R, Cannon BR, Sorci G, Riuzzi F, Hsu K, Weber DJ, Geczy CL (2013) Functions of S100 proteins. Curr Mol Med 13: 24-57

Ebersoldt M, Sharshar T, Annane D (2007) Sepsis-associated delirium. Int Care Med 33: 941-950. doi: 10.1007/s00134-007-0622-2

Goyal A, Failla MD, Niyonkuru C, Amin K, Fabio A, Berger RP, Wagner AK (2013) S100b as a prognostic biomarker in outcome prediction for patients with severe traumatic brain injury. I Neurotrauma 30: 946-957. doi: 10.1089/neu.2012.2579

Hamed SA, Hamed EA, Abdella MM (2009) Septic encephalopathy: relationship to serum and cerebrospinal fluid levels of adhesion molecules, lipid peroxides and S-100B protein. Neuropediatrics 40: 66-72. doi: 10.1055/s-0029-1231054

Herrmann M, Curio N, Jost S, Wunderlich MT, Synowitz H, Wallesch CW (1999) Protein S-100B and neuron specific enolase as early neurobiochemical markers of the severity of traumatic brain injury. Restor Neurol Neurosci 14: 109-114

Iacobone E, Bailly-Salin J, Polito A, Friedman D, Stevens RD, Sharshar T (2009) Sepsis-associated encephalopathy and its differential diagnosis. Crit Care Med 37: S331-S336. doi: 10.1097/ CCM.0b013e3181b6ed58

Jensen JU, Heslet L, Jensen T H, Espersen K, Steffensen P, Tvede M (2006) Procalcitonin increase in early identification of critically ill patients at high risk of mortality. Crit Care Med 34: 2596-2602. doi: 10.1097/01.CCM.0000239116.01855.61

Karnak D, Beder S, Kayacan O, Ibiş E, Oflaz G (2005) Neuron-specific enolase and lung cancer. Am J Clin Oncol 28: 586-590

Knaus WA, Zimmerman JE, Wagner DP, Draper EA, Lawrence DE (1981) APACHE-acute physiology and chronic health evaluation: a physiologically based classification system. Crit Care Med 9: 591-597

Korfias S, Stranjalis G, Papadimitriou A, Psachoulia C, Daskalakis G, Antsaklis A, Sakas DE (2006) Serum S-100B protein as a biochemical marker of brain injury: a review of current concepts. Curr Med Chem 13: 3719-3731. doi: 10.2174/092986706779026129

Korfias S, Stranjalis G, Boviatsis E, Psachoulia C, Jullien G, Gregson B, Mendelow AD, Sakas DE (2007) Serum S-100B protein monitoring in patients with severe traumatic brain injury. Int Care Med 33: 255-260

Krzych ŁJ, Czempik PF, Saucha W, Kokocińska D, Knapik P (2015) Serum S100B protein concentration in brain-dead organ donors: a pilot study. Anaesthesiol Intensive Ther 47: 320-323. doi: 10.5603/ AIT.2015.0041

Macedo RC, Tomasi CD, Giombelli VR, Alves SC, Bristot MLU, Locks MFT, Ritter C (2013) Lack of association of S100 $\beta$ and neuron-specific enolase with mortality in critically ill patients. Rev Bras Psiquiatr 35: 267-270

Marshall JC, Reinhart K (2009) Biomarkers of sepsis. Crit Care Med 37: 2290-2298. doi: 10.1097/CCM.0b013e3181a02afc

Mercier E, Boutin A, Lauzier F, Fergusson DA, Simard JF, Zarychanski R, Légaré F (2013) Predictive value of S-100 $\beta$ protein for prognosis in patients with moderate and severe traumatic brain injury: systematic review and meta-analysis. BMJ 346: f1757. doi: 10.1136/ bmj.f1757

Michetti F, Corvino V, Geloso MC, Lattanzi W, Bernardini C, Serpero L, Gazzolo D (2012) The S100B protein in biological fluids: more than a lifelong biomarker of brain distress. I Neurochem 120: 644 659. doi: 10.1111/j.1471-4159.2011.07612.x

Nguyen DN, Spapen H, Su F, Schiettecatte J, Shi L, Hachimi-Idrissi S, Huyghens L (2006) Elevated serum levels of S-100 $\beta$ protein and neuron-specific enolase are associated with brain injury in patients with severe sepsis and septic shock. Crit Care Med 34: 1967-1974. doi: 10.1097/01.CCM.0000217218.51381.49

Nguyen HB, Loomba M, Yang JJ, Jacobsen G, Shah K, Otero RM, Rivers EP (2010) Early lactate clearance is associated with biomarkers of inflammation, coagulation, apoptosis, organ dysfunction and mortality in severe sepsis and septic shock. J Inflamm 7. doi: 10.1186/1476-9255-7-6

Papadopoulos MC, Davies DC, Moss RF, Tighe D, Bennett ED. (2000) Pathophysiology of septic encephalopathy: a review. Crit Care Med 28: 3019-3024

Pfortmueller CA, Drexel C, Krähenmann-Müller S, Leichtle AB, Fiedler GM, Lindner G, Exadaktylos AK (2016) S-1001B concentrations are a predictor of decreased survival in patients with major trauma, independently of head injury. PLoS One 31: e0152822. https://doi. org/10.1371/journal.pone.0152822

Rodríguez-Rodríguez A, Egea-Guerrero JJ, León-Justel A, GordilloEscobar E, Revuelto-Rey J, Vilches-Arenas Á, Guerrero J M (2012) Role of S100B protein in urine and serum as an early predictor of mortality after severe traumatic brain injury in adults. Clin Chim Acta 414: 228-233. doi: 10.1016/j.cca.2012.09.025

Routsi C, Stamataki E, Nanas S, Psachoulia C, Stathopoulos A, Koroneos A, Roussos C (2006) Increased levels of serum S100B protein in critically ill patients without brain injury. Shock 26: 20-24. doi: 10.1097/01.shk.0000209546.06801.d7

Satoh H, Ishikawa H, Kurishima K, Yamashita YT, Ohtsuka M, Sekizawa K.(2002) Cut-off levels of NSE to differentiate SCLC from NSCLC. Oncology Rep 9: 581-583

Siman R, Giovannone N, Toraskar N, Frangos S, Stein SC, Levine JM, Kumar MA (2011) Evidence that a panel of neurodegeneration biomarkers predicts vasospasm, infarction, and outcome in aneurysmal subarachnoid hemorrhage. PLoS One 6: e28938. https://doi. org/10.1371/journal.pone.0028938

Stocchetti N (2005) Brain and sepsis: functional impairment, structural damage, and markers. Anesth Analg 101: 1463-1464. doi: 10.1213/01. ANE.0000181337.03655.0C

Stranjalis G, Korfias S, Papapetrou C, Kouvialis A, Boviatsis E, Psachoulia C, Sakas DE (2004) Elevated serum S-100B protein as a predictor of failure to short-term return to work or activities after mild head injury. I Neurotrauma 21: 1070-1075. doi: 10.1089/0897715041651088

Vincent JL, de Mendonca A, Cantraine F, Moreno R, Takala J, Suter P M, Sprung C L, Colardyn F, Blecher S (1998) Use of the SOFA score to assess the incidence of organ dysfunction/failure in intensive care units: Results of a multicenter, prospective study. Crit Care Med 26: 1793-1800

Weigand MA, Volkmann M, Schmidt H, Martin E, Böhrer H, Bardenheuer HJ (2000) Neuron-specific enolase as a marker of fatal outcome in patients with severe sepsis or septic shock. Anesthesiology 92: 905-905

Weigl W, Adamski J, Goryński P, Kański A, Hultström M (2017) Mortality rate is higher in Polish intensive care units than in other European countries. Int Care Med (e-pub ahead of print) doi: 10.1007/ s00134-017-4804-2

Xu L, Lina W, Xuejun Y (2016) The diagnostic value of serum CEA, NSE and MMP-9 for on-small cell lung cancer. Open Med 11: 59-62

Yao B, Zhang LN, Ai YH (2014) Serum S100ß is a better biomarker than neuron-specific enolase for sepsis-associated encephalopathy and determining its prognosis: a prospective and observational study. Neurochem Res 39: 1263-1269. doi: 10.1007/s11064-014-13080

Zongo D, Ribéreau-Gayon R, Masson F, Laborey M, Contrand B, Salmi LR, Montaudon D, Beaudeux JL, Meurin A, Dousset V, Loiseau H, Lagarde E (2012) S100-B protein as a screening tool for the early assessment of minor head injury. Ann Emerg Med 59: 209-218. doi: $10.1016 /$ j.annemergmed.2011.07.027 